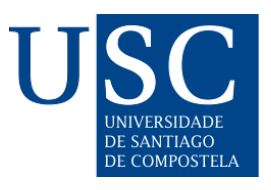

\title{
Seguridad(es) en un futuro incierto. Un estudio jurídico constitucional
}

\author{
Daniel Sansó-Rubert Pascual \\ Secretario Gladius et Scientia. Revista de Estudios de Seguridad, Universidad de Santiago de Compostela, España \\ daniel.sanso-rubert@usc.es
}

A través de un título sugerente, Seguridad(es) en un futuro incierto. Un estudio jurídico constitucional, el Prof. José Julio Fernández Rodríguez de la mano de la prestigiosa editorial Thomson Reuters-Aranzadi, aborda con sencillez expresiva, pero sin perder ni un ápice de rigor técnico y cuidado análisis académico, una temática a todas luces actual, de indiscutible vigencia.

La lectura de este trabajo contribuye a una clara comprensión del proceloso mundo de la seguridad, que como bien identifica y desmenuza el autor, realmente de lo que se trata es de un conjunto de seguridades de muy variada naturaleza y con objetivos igualmente diversos, que configuran en su conjunto ese halo protector al que denominamos seguridad, como si de un todo unitario se tratase.

Este análisis se organiza en cinco grandes apartados, siguiendo un cuidado planteamiento estructurado y coherente, que facilita su lectura ágil y comprensiva, manteniendo la atracción del lector cautiva a lo largo de todo el hilo argumental. Estas cinco versan grosso modo sobre las seguridad(es), los problemas a enfrentar en la actualidad, las respuestas dadas y, en último término, las soluciones propuestas. Finalmente, cierran la obra unas conclusiones que refuerzan el razonamiento elaborado.

Destacar, el esfuerzo del autor por simplificar con éxito cuestiones complejas, sin menoscabo del rigor académico y tratar en todo momento de recurrir a la explicación de la realidad imperante, a través del recurso continuo a la referencia de noticias aparecidas en los medios, a pesar de no ser una práctica académica habitual. Recurso, que sin duda resulta atractivo, tanto para un lector curioso pero menos avezado en las cuestiones de seguridad, como para el experto, que puede constatar la ejemplificación del análisis elaborado con el aporte de informaciones complementarias, al referenciar no sólo noticias, sino por igual, normas y documentos oficiales, además de trabajos doctrinales. Un elenco de fuentes que, hábilmente conjugadas, contribuyen a construir un conjunto de reflexiones sólidamente documentadas.

Ahondando en el contenido, Fernández Rodríguez pone de manifiesto cómo en su conjunto, el concepto de Seguridad ha evolucionado en las últimas décadas a un ritmo vertiginoso, marcado por un proceso de profunda reconfiguración del orden internacional.

El presente libro, trata de ofrecer un análisis realista y libre de las intrincadas cuestiones de la seguridad actual, sin los encorsetamientos o deudas que imponen las ideas de lo políticamente correcto y de los tópicos que dimanan de ellas. El autor, ha asumido con este trabajo el compromiso, 
desde la honestidad intelectual, de contribuir al avance del conocimiento crítico e informado para que la seguridad demandada por la sociedad coincida, en la medida de lo posible, con la verdadera seguridad que ésta necesita.

Quizá el nudo gordiano de la obra a destacar, de entre las diversas respuestas planteadas a la problemática de seguridad, sea el conseguir un equilibrio adecuado entre seguridad y libertad. La relación entre seguridad y derechos (libertad), como identifica el autor, no sólo se caracteriza a priori por su complejidad. Sin ánimo ahora de examinar todas sus aristas, analizadas en profundidad en el libro, podemos decir que el Prof. Fernández Rodríguez sustancia ésta en dos líneas: por un lado, una relación en negativo y, por otro, en positivo. La primera alude a una dialéctica contrapuesta entre seguridad y derechos fundamentales, o sea, entre seguridad y libertad, de manera tal que el aumento de una mengua a la otra. En el sentido positivo la relación entre ambas categorías es complementaria: a mayor seguridad mejor ejercicio de los derechos fundamentales. Los dos sentidos tienen aplicación al mismo tiempo. En todo caso, sin olvidar el punto de partida: la consideración de los derechos fundamentales como base del sistema sociojurídico.

Además del planteamiento de este sempiterno debate entre la seguridad y la libertad, analizado, en todo caso, desde un prisma novedoso que le confiere una importante carga de originalidad, cabe reseñar, de entre todos los aspectos notables de este trabajo, su último apartado, en el que se aborda con singularidad la propuesta de una posible reforma de la Carta Magna española en conexión con el objeto de este libro.

El asunto de las reformas constitucionales es, como se comprenderá, de envergadura. La definición sostenida de este tipo de normas ilustra su trascendencia (y, por lo tanto, de cualquier modificación que se acometa): una constitución, en sentido propio, es una norma jurídica suprema y abierta que, por un lado, organiza el poder político, estableciendo mecanismos de control del mismo y, por otro, regula los aspectos esenciales de la sociedad desde unos postulados democráticos (a través de la previsión de derechos fundamentales). Por lo que cualquier iniciativa de reforma debe ser objeto de reflexión y debate constructivo y equilibrado para evitar, en última instancia, deslizarse por los derroteros de la desproporción de la respuesta, tan perjudicial para la garantía de los derechos fundamentales.

La propuesta pergeñada por Fernández Rodríguez sobre una necesaria reforma de la Constitución Española en relación con los temas de seguridad debe conectarse, por un lado, con la necesaria revitalización de la democracia actual y, por otro, con la exigencia previa de la necesaria concurrencia del suficiente consenso político que propicie tal reforma. Cuestión no precisamente baladí, en los tiempos convulsos por los que transita la política española en los últimos años. Lo cual, también debe llevarnos a la reflexión de la relevancia de las políticas de seguridad del Estado, más allá de las visiones netamente partidistas. En definitiva, como recalca el autor, la reforma de nuestra Carta Magna debe suscitar los mayores apoyos posibles, no sólo para cubrir las mayorías precisas para llevarla a cabo, sino especialmente para dotarla de legitimidad.

En concreto, la propuesta de modificación del articulado constitucional reflejada en esta obra, efectúa un recorrido por diversos preceptos constitucionales constatando un ejercicio de dominio normocreativo en sintonía con las exigentes técnicas de redacción constitucional, -mucho más necesitadas de claridad por la función pedagógica que también debería desempeñar una carta magna-, cuyo resultado son propuestas de mejora del actual texto constitucional. Mejoras, enfocadas al área de seguridad que nos ocupa, que reforzarían, sin lugar a dudas, la calidad de la respuesta ante los desafíos y amenazas que atenazan el Estado social y democrático de derecho, así como los valores y principios democráticos que lo inspiran. 
Los problemas de seguridad son distintos y de diversa índole. Están relacionados entre sí, implicándose mutuamente y condicionándose. Entre ellos encontramos tanto concretas amenazas actuales, como riesgos, desafíos o debilidades. Y también son situaciones que afecta a específicos derechos fundamentales, vulnerándolos o sometiéndolos a escenarios de difícil garantía.

Las respuestas a las amenazas y riesgos adoptadas son muchas, de diferente sentido, intensidad y naturaleza. De algunas aún está por ver su eficacia. Otras sí han sido positivas en cuanto al esfuerzo de renovación del planteamiento estratégico y de compromiso con los derechos y libertades frente a los radicales. En todo caso, en términos de legislación, hay que exigir una correcta técnica, que cumpla con los estándares democráticos y que permita la actualización de la normativa. Y en el ámbito político, hay que reclamar actuaciones en aras del interés general, decididas en defensa de los valores y principios del constitucionalismo y situadas en el respeto al Estado de Derecho.

En virtud de lo ya expresado, entendemos que ha quedado claro que estamos hablando de temas de indudable relevancia constitucional, que por tal razón deben abordarse con esa óptica y metodología. Lo cual es un acierto por parte del autor. Es decir, se trata de temas que deben ser objeto de decisiones básicas del poder público, lo que, por ese motivo, tendrían que estar, de una $\mathrm{u}$ otra forma, presentes en el texto constitucional. Por tal motivo, el enfoque adoptado en el texto responde especialmente a una perspectiva jurídico-constitucional, aunque no exclusiva, ya que el autor emplea con maestría de igual forma, enfoques politológicos, geoestratégicos, sociológicos y de otras ramas jurídico-públicas. La complejidad de las cuestiones abordadas en esta obra, su propia heterogeneidad y naturaleza, además de su solapamiento, obligan a complementar el método de análisis base empleado -el jurídico constitucional-, con otros auxiliares. Y es que, no puede obviarse que la problemática del presente que vivimos requiere respuestas satisfactorias, que no siempre se producen. Como apunta el Prof. Fernández Rodríguez con exquisita clarividencia, estamos, por lo tanto, necesitados de enfoques en parte nuevos para prosperar y evolucionar. Enfoques complejos, multidimensionales y críticos, que se liberen de la pesada carga de lo políticamente correcto y de la desinformación que envuelve a parte de nuestra sociedad.

Y en esta línea, el método jurídico-constitucional empleado es particularmente útil para enfrentarse a este tipo de objetos de estudio, caracterizados por la interdisciplinariedad, y que evolucionan con avidez cambiante y, en cierto modo, holística. Resultado: un producto útil e interesante en su conjunto.

En síntesis, un análisis profundo, reforzado con conclusiones certeras de quien es un riguroso estudioso y reputado experto del constitucionalismo. Hacía falta que, al acervo académico relativo a la Seguridad, tan extenso en otros enfoques, se le sumara el mucho menos habitual de los estudios constitucionales. Deuda saldada.

\section{Información Adicional:}

Título: Seguridad(es) en un futuro incierto. Un estudio jurídico constitucional

Autor: José Julio Fernández Rodríguez

Editorial: Thomson Reuters-Aranzadi

Año de edición: 2020

Páginas: 236

ISBN: 978-84-1345-278-4 